\title{
Social Comparison of Tribal Groups Based on Wadi Project Adoption
}

\author{
Anupam Dakua ${ }^{1 *}$, R. N. Das ${ }^{2}$ and Kalyan Ghadei ${ }^{3}$ \\ ${ }^{1}$ Department of Extension Education, Institute of Agricultural sciences, Banaras Hindu \\ University, Varanasi-221005, Uttar Pradesh, India \\ ${ }^{2}$ Department of Extension Education, Orissa University of Agriculture and Technology, \\ Bhubaneswar-751003, Odisha, India \\ *Corresponding author
}

\section{A B S T R A C T}

\section{Keywords}

Cosmopoliteness, Livelihood, Mass media, Tribal, WADI

\section{Article Info}

Accepted:

10 July 2020

Available Online:

10 August 2020
WADI project, though the name derived from a Gujarati term for orchards, works as a livelihood project for socio-economic development of tribal people throughout India. Being funded by NABARD and in Odisha implemented by ITDA, it is operationalised in most of the tribal dominated districts and is a holistic approach for the sustainable development of tribal livelihood. Ex Post Facto Study conducted in Champua Subdivision of Keonjhar district of Odisha taking the WADI adopting and WADI non-adopting tribal people as respondents shows the differences in development of both the groups. The data collected from the respondents is analysed for the comparison of certain social characteristic of both the groups. The result obtained from the study is very interesting and encouraging for livelihood projects like WADI. Amongst the variables studied under the social attributes like Cosmopoliteness, Social participation, organisational participation, Extension participation, Extension Contact, Mass media exposure, in most cases the WADI adopters supersede the non-adopter ones. Hence, promotion of livelihood project like WADI should be encouraged by the Government for the sustainable development of tribal people in our country.

\section{Introduction}

The report on Statistical profile of Schedule tribes in India, 2013 states that 705 number of tribes are inhabiting in 30 states/ UTs all over India. As per the 2011 census data, their number was 10.43 crores which accounted for 6.8 percent of the total population of the country. Out of these, $89.97 \%$ of them live in rural areas and $10.03 \%$ in urban areas. Broadly they inhabit two distinct geographical area - the Central India and the NorthEastern Area. More than half of them are concentrated in Central India, i.e., Madhya Pradesh (14.69\%), Chhattisgarh (7.5\%), Jharkhand (8.29\%), Andhra Pradesh (5.7\%), Maharashtra (10.08\%), Orissa (9.2\%), Gujarat $(8.55 \%)$ and Rajasthan $(8.86 \%)$. The diagram 
below represents their concentration over the Indian Landmass.

It is very much evident from the above diagram that majority of these tribal people belong to the central India especially to the states like Madhya Pradesh, Chhattisgarh and Odisha.

The resources and livelihood group, Prayas, Pune in its report "A Study on the Livelihoods Situation Of the Tribal Communities in Raigad District of Maharashtra State" in 2005 sates that in spite of pursuing rapid economic development for more than five decades India since independence the objective of poverty eradications has not yet been achieved. The marginalised sections especially the tribal people are the worst affected among them.

On this background the Government of India has initiated many programmes and policies. One such aspect of the development is the functionalisation of ITDA (Integrated Tribal Development Agency) since the Fifth Five Year Plan period. The main objective of ITDA is socio-economic development of tribal communities through income generating schemes allied with Infrastructure Development programmes and protection of the tribal communities against exploitation. It is a platform to cater the needs of the tribal community by taking up of various livelihood activities as well community development in convergence with line departments support meant for the upliftment of the downtrodden tribal community. Among the many line of action of the ITDA the WADI project is one of them which aims at the economic upliftment of the tribal people through sustainable agriculture, social empowerment, improvement in quality of life including health and women empowerment in tribal dominated areas of the country. The broad interventions are in the areas of land use planning, soil and water harvesting measures and improved farming based agro-forestry practices. Therefore, WADI not only strengthens the agrarian livelihoods of the tribal households, but also increases food and nutritional security of the nation.

WADI in Guajarati language means a 'small orchard' covering one or two acres. In this project it is intended to promote orchard development among the tribal communities. It is envisaged as family centric agriculture where the emphasis is on small land holdings (1-2 acres), agro-biodiversity and greater participation of women.

This paper, an original research work, tries to study the impact of WADI project on certain social aspect of the tribal population by comparing the WADI adopted tribal people with the Non-adopted ones.

\section{Materials and Methods}

Following the Ex-post-facto research design, the study was conducted in Champua Subdivision of Keonjhar District of Odisha. Champua, being a tribal majority Subdivision of the District, was selected purposively. Among the various tribal people Ho, Juang, Bhuinya, Oraon, Gond, Bhumij an d other tribal communities constituted nearly $87.21 \%$ population of the Sub-division. All the three blocks namely Joda, Champua and Jhumpura were taken as the sampling area for data collection. Four tribal villages from each block i.e. two WADI adopted villages and two non-adopted villages were taken randomly for the data collection. From all the tribal households 10 respondents from each village were taken randomly and by this 120 respondents, 60 WADI adopted and 60 nonadopted were taken from the Subdivision. A pretested semi-structured interview schedule was used for the data collection. The data so collected were analysed using suitable 
statistical tools and interpreted. In this paper the social aspect like Cosmopoliteness, Social participation, organisational participation, Extension participation, Extension Contact, Mass media exposure of the WADI adopted tribal people were compared with the nonadopted ones to get the better site of the social differences between the two groups.

\section{Result and Discussion}

\section{Cosmopoliteness}

It is clear from Table 1 among WADI adopting respondents majority $(66.7 \%)$ were medium cosmopolite following 30 percent were highly cosmopolite and only 3.3 percent were low cosmopolite. While in case of WADI non adopting respondents majority (60\%) were medium cosmopolite following 25 percent low cosmopolite and only 15 percent were high cosmopolite.

Hence, considering the above analysis it can be concluded that the WADI adopting tribal people are comparatively more cosmopolite than the other group.

\section{Purpose of cosmopoliteness}

Table 2 indicates that among the WADI adopting tribal people majority (45\%) visited to the nearest towns for agriculture related activities followed by 38.3 percent visited for personal and domestic purpose and the rest 16.7 percent visited for non-agricultural purpose. No WADI adopters were visiting for entertainment purposes. But in case of the WADI non-adopting tribal groups majority (38.4\%) visited for non-agriculture purpose followed by 33.3 for domestic purpose, 20 percent for agriculture related activities and 8.3 percent for entertainment purpose.

It is clear that a greater number of WADI adopting tribal people visited outside the society for agricultural activities compared to the other group, hence they were very active in agricultural activities. It reflects the occupational orientation in WADI adopting tribal group compared to the non-adopting ones.

\section{Social participation}

Table 3 indicates that among the WADI adopting tribal people most $(78.3 \%)$ of the respondents were having medium level of social participation followed by 21.7 percent were having high participation. None of the WAFI adopters were having low level of participation. On the other hand, in case of the WADI non-adopting ones most $(51.7 \%)$ were having medium level of social participation, followed by 41.6 percent low and only 7.7 percent high social participation.

The low participation of WADI adopters was nil while it was more in case of the WADI non adopters. Again, high participation level was more in case of WADI tribal people than the other group. Hence, it is concluded that the tribal people who has adopted WADI project were actively participated in social activities than those who have not adopted it.

Table 4 indicates that for WADI adopters social function was the most participated activities having highest mean score (2.88) followed by collective work having mean score of 1.90, developmental activities having mean score of 1.87 , village decision making having mean score 1.52 and the fifth ranked activity was vocational training having mean vale 1.33. In case of the WADI non adopting tribal people the first ranked activity was social function having mean score of 1.92 followed by developmental activities having mean score of 1.62 , collective work having mean score of 1.55 and the fourth ranked activity was both village decision making and vocational training having mean score of 1.17 . 
As a result, it is clear that most of the tribal people whether WADI adopters or nonadopters participated in social functions. Second mean score in case of WADI adopters was of collective work signified the high extent of cooperation prevailing among them and their attitude to form social groups. For developmental activities the mean score was high for the first group. Hence, they were very prone to development. Considering the village decision making it is clear that they were also very active in this activity.

\section{Participation in organization}

The participation of tribal people in the study area in various organisation like village committee, youth club, village information centre, SHG, panchayat office, Zilla parishad, etc.

Table 5 indicates that majority (43.3\%) participation level of WADI adopting tribal people have both medium and high level of participation in social organization where as 13.4 percent belonged to low level of participation. On the other hand, for WADI non- adopter majority (80\%) were having medium level of participation followed by 11.7 percent for low level and only 8.3 percent for high level of participation in social organizations.

Here it is clear that participation level of WADI adopting tribal ones in the study area were very high in social organizations. It is hence concluded that the WADI adopters generally prefer to take lead in the social organizations in comparison to other groups.

Table 6 indicates that among the WADI adopters first ranked participation was SHG having mean score of 2.62, followed by village committee (means score: 1.87), youth club (means score: 1.43), village information centre (VIC) (means score: 1.27), Panchayat office (means score: 1.18), block office (means score: 1.17) and the last rank order was given to Zilla parishad (means score: 1.08). But, the participation in social organization for WADI non-adpting tribal [people the first ranked organization was village committee (means score: 1.53) followed by youth club (means score: 1.32), SHG (means score: 1.27), Panchayat office and block office (both having means score: 1.17) and the last ranked organization was Zilla parishad (means score: 1.03).

The preferred participating in SHGs for the WADI adopters shows their interest towards livelihood generating and economic developing organization. Participation of tribal people in such organization should be motivated and encouraged for their sustainable source of income. Both the groups under study were less actively involved themselves in government organizations such as panchayat office, block office and Zilla parishad office due to the tribal's attitude to work independently.

\section{Extension participation}

The participation of tribal people in the study area in various extension activities like farmers' training, demonstration, exhibition, exposure visit, awareness campaign, farmers' fair etc.

Table 7 clarifies that among WADI respondent majority (60\%) belonged to medium category followed by 28.3 percent in high and 11.7 percent in low category with respect to participation in extension activities. But in case of WADI non-adopting tribal people majority $(75 \%)$ belonged to high category followed by 16.7 percent in low category and only 8.3 percent in high category of participation in extension activities. 
The high level of participation in extension activities was shown by the WADI adopting tribal ones signifies their active participation in extension activities as compared to the other group.

Table 8 indicates that for the WADI adopting tribal people in the study area most preferred extension activity was Farmers' fair (means score: 1.98) followed by farmers' training (means score: 1.95), Exhibition and exposure visit (both having means score of 1.83), demonstration and awareness campaign (both having means score of 1.57). on the other hands, for WADI non-adopter most preferred extension activity is farmers' fair (means score: 1.65) followed by farmers' training (means score: 1.57), awareness campaign (means score: 1.27) demonstration and Exposure visit (means score: 1.22) and the least preferred extension activity was Exhibition (means score: 1.17).

It signifies that WADI adopting respondents prefer the achievement of knowledge, skill improvement regarding the agricultural activities and horticultural operation includes the orchard management. They attached equal importance to exhibitions and exposure visit. Lastly they treated demonstration and awareness campaign equal score. The dissimilarity in trend shown by the WADI non-adopters was because their localite nature and most of these extension activities was held outside of their locality.

\section{Extension contact}

The extension contact of tribal people in the study area in various extension organizations like VAW/LVAW/AO, AAO, SMS of KVK, district level officials like OTELP or ITDA, state level officials like officers of SCSTRTI, etc.

Table 9 indicates that among WADI adopting respondent majority (55\%) belonged to medium category followed by 31.7 percent in high and 13.3 percent in low category with request to extension contact with extension agents of various organizations. On the other hand from WADI non-adopters majority $(58.3 \%)$ belonged to medium category followed by 36.7 percent in low and only 5 percent in low category of the extension contact with the extension agents of various organizations.

Hence, it reflects that the WADI adopting tribal people are very actively remain in contact with the extension agents of various extension organization than the other group.

Table 10 shows that the WADI adopters had most preferred extension agents were VAW/LVAW/AO (mean score: 2.32) followed by AAO (mean score: 1.80), District level officials (mean score: 1.60), state level officials (mean score: 1.38) and the lease preferred ones were the KVK SMS (mean score: 1.28). But in case of the WADI nonadopters the most preferred extension agents were VAW/LVAW/AO (mean score: 2.20) followed by AAO (mean score: 1.87), KVK SMS (mean score: 1.53) District level officials (mean score: 1.38) and the least preferred ones were state level officials (mean score: 1.12 )

It is clear that in case of WADI adopters contact level is appreciable with the district level officials as for WADI activities, trainings and further assistance they have to be dependent on them. Again they are cosmopolite in nature so they also contact the state level officials.

\section{Mass media exposure}

The use of mass media as the source of information by the tribal people in the study area are Newspaper, periodicals, radio, television, films, etc. 
From the Table 11 it can be concluded that from the WADI adopting tribal people majority $(56.7 \%)$ belonged to medium category followed by 35 percent in high category and 8.3 percent in low category in respect to the use of mass media as source of information. But on the other hand in case of the WADI non-adopting tribals majority (53.3\%) belonged to medium followed by 33.4 percent in low category and 13.3 percent in high category for the use of mass media.

Table.1 Distribution of tribals according to the Status of cosmopoliteness

\begin{tabular}{|l|l|c|c|c|c|}
\hline SI & Category & \multicolumn{2}{|c|}{ WADI adopters } & \multicolumn{2}{|c|}{ WADI non adopters } \\
\cline { 3 - 6 } no & & Frequency & Percentage & Frequency & Percentage \\
\hline $\mathbf{1}$ & Low & 2 & 3.3 & 15 & 25 \\
\hline $\mathbf{2}$ & Medium & 40 & 66.7 & 36 & 60 \\
\hline $\mathbf{3}$ & High & 18 & 30 & 9 & 15 \\
\hline \multicolumn{2}{|l|}{ Total } & $\mathbf{6 0}$ & $\mathbf{1 0 0}$ & $\mathbf{6 0}$ & $\mathbf{1 0 0}$ \\
\hline
\end{tabular}

$\mathrm{MAEN}=3.12 \quad, \mathrm{SD}=1.49$

Table.2 Purpose of cosmopoliteness of the tribal people

\begin{tabular}{|l|c|c|c|c|}
\hline \multirow{2}{*}{ Purpose of visit } & \multicolumn{2}{|c|}{ WADI adopters } & \multicolumn{2}{c|}{ WADI non-adopters } \\
\hline & Frequency & Percentage & Frequency & Percentage \\
\hline $\begin{array}{l}\text { All related to } \\
\text { Agriculture }\end{array}$ & 27 & 45 & 12 & 20 \\
\hline $\begin{array}{l}\text { Personal or } \\
\text { domestic }\end{array}$ & 23 & 38.3 & 20 & 33.3 \\
\hline $\begin{array}{l}\text { Non agricultural } \\
\text { purpose }\end{array}$ & 10 & 16.7 & 23 & 38.4 \\
\hline Entertainment & - & - & 5 & 8.3 \\
\hline
\end{tabular}

Table.3 Social participation of the tribal people

\begin{tabular}{|l|l|c|c|c|c|}
\hline \multirow{2}{*}{$\begin{array}{l}\text { nI } \\
\text { no }\end{array}$} & Category & \multicolumn{2}{|c|}{ WADI adopter } & \multicolumn{2}{|c|}{ WADI non adopter } \\
\hline & & Frequency & Percentage & Frequency & Percentage \\
\hline $\mathbf{1}$ & Low & 00 & 0.0 & 25 & 41.6 \\
\hline $\mathbf{2}$ & Medium & 47 & 78.3 & 31 & 51.7 \\
\hline $\mathbf{3}$ & High & 13 & 21.7 & 4 & 7.7 \\
\hline Total & & $\mathbf{6 0}$ & $\mathbf{1 0 0}$ & $\mathbf{6 0}$ & $\mathbf{1 0 0}$ \\
\hline
\end{tabular}


Table.4 Status of tribal population in social participation

\begin{tabular}{|l|c|c|c|c|}
\hline \multirow{2}{*}{ Activity } & \multicolumn{2}{|c|}{ WADI adopter } & \multicolumn{2}{c|}{ WADI non adopter } \\
\cline { 2 - 5 } & Mean score & Rank order & Mean score & Rank order \\
\hline $\begin{array}{l}\text { Village decision } \\
\text { making }\end{array}$ & 1.52 & 4 & 1.17 & 4 \\
\hline Collective work & 1.90 & 2 & 1.55 & 3 \\
\hline $\begin{array}{l}\text { Developmental } \\
\text { activity }\end{array}$ & 1.87 & 3 & 1.62 & 1 \\
\hline Social function & 2.88 & 1 & 1.92 & 4 \\
\hline $\begin{array}{l}\text { Vocational } \\
\text { training }\end{array}$ & 1.33 & 5 & 1.17 & \\
\hline
\end{tabular}

Table.5 Participation of the tribal people in social organizations

\begin{tabular}{|l|l|c|c|c|c|}
\hline Sl. no & category & \multicolumn{2}{|c|}{ WADI adopters } & \multicolumn{2}{|c|}{ WADI non-adopters } \\
\cline { 3 - 6 } & & Frequency & Percentage & Frequency & Percentage \\
\hline $\mathbf{1}$ & Low & 8 & 13.4 & 7 & 11.7 \\
\hline $\mathbf{2}$ & Medium & 26 & 43.3 & 48 & 80 \\
\hline $\mathbf{3}$ & High & 26 & 43.3 & 5 & 8.3 \\
\hline Total & & $\mathbf{6 0}$ & $\mathbf{1 0 0}$ & $\mathbf{6 0}$ & $\mathbf{1 0 0}$ \\
\hline
\end{tabular}

Table.6 Status of tribal population in participation in social organizations

\begin{tabular}{|l|c|c|c|c|}
\hline \multirow{2}{*}{ Activity } & \multicolumn{2}{|c|}{ WADI adopters } & \multicolumn{2}{c|}{ WADI non adopter } \\
\cline { 2 - 5 } & Mean score & Rank order & Mean score & Rank order \\
\hline Village & 1.87 & 2 & 1.53 & 1 \\
\hline Yommittee & & & & 2 \\
\hline YIC & 1.43 & 3 & 1.32 & 5 \\
\hline SHG & 1.27 & 4 & 1.17 & 3 \\
\hline Panchyat office & 2.62 & 1 & 1.27 & 4 \\
\hline Block office & 1.18 & 5 & 1.17 & 5 \\
\hline Zilla parishad & 1.17 & 6 & 1.03 & 6 \\
\hline
\end{tabular}

Table.7 Participation of the tribal people in extension activities

\begin{tabular}{|l|l|c|c|c|c|}
\hline \multirow{2}{*}{ SI. no } & Category & \multicolumn{2}{|c|}{ WADI adopters } & \multicolumn{2}{|c|}{ WADI non adopters } \\
\cline { 3 - 6 } & & Frequency & Percentage & Frequency & Percentage \\
\hline $\mathbf{1}$ & Low & 7 & 11.7 & 10 & 16.7 \\
\hline $\mathbf{2}$ & Medium & 36 & 60 & 45 & 75 \\
\hline $\mathbf{3}$ & High & 17 & 28.3 & 5 & 8.3 \\
\hline Total & & 60 & 100 & 60 & 100 \\
\hline
\end{tabular}


Table.8 Status of tribal people in participation in extension activities

\begin{tabular}{|l|c|c|c|c|}
\hline \multirow{2}{*}{ Activity } & \multicolumn{2}{|c|}{ WADI adopters } & \multicolumn{2}{c|}{ WADI non adopters } \\
\cline { 2 - 5 } & Mean score & Rank order & Mean score & Rank order \\
\hline $\begin{array}{l}\text { Farmers' } \\
\text { training }\end{array}$ & 1.95 & 2 & 1.57 & 2 \\
\hline Demonstration & 1.57 & 4 & 1.22 & 4 \\
\hline Exhibition & 1.83 & 3 & 1.17 & 5 \\
\hline Exposure visit & 1.83 & 3 & 1.22 & 3 \\
\hline $\begin{array}{l}\text { Awareness } \\
\text { campaign }\end{array}$ & 1.57 & 4 & 1.27 & 1 \\
\hline Farmers' fair & 1.98 & 1 & 1.65 & \\
\hline
\end{tabular}

Table.9 Extension contact of tribal population with extension agents of various organization

\begin{tabular}{|l|l|c|c|c|c|}
\hline Sl. no & category & \multicolumn{2}{|c|}{ WADI adopters } & \multicolumn{2}{|c|}{ WADI non adopters } \\
\cline { 3 - 6 } & & Frequency & Percentage & Frequency & Percentage \\
\hline $\mathbf{1}$ & Low & 8 & 13.3 & 22 & 36.7 \\
\hline $\mathbf{2}$ & Medium & 33 & 55 & 35 & 58.3 \\
\hline $\mathbf{3}$ & High & 19 & 31.7 & 3 & 5 \\
\hline Total & & $\mathbf{6 0}$ & $\mathbf{1 0 0}$ & $\mathbf{6 0}$ & $\mathbf{1 0 0}$ \\
\hline
\end{tabular}

MEAN $=11.84, \mathrm{Sd}=1.81$

Table.10 Status of tribals in extension contact of various extension functionaries

\begin{tabular}{|l|c|c|c|c|}
\hline \multirow{2}{*}{ Extension Agents } & \multicolumn{2}{|c|}{ WADI adopters } & \multicolumn{2}{c|}{ WADI non adopters } \\
\cline { 2 - 5 } & Mean score & Rank order & Mean score & Rank order \\
\hline VAW/LVAW/AO & 2.32 & 1 & 2.20 & 1 \\
\hline AAO & 1.80 & 2 & 1.87 & 2 \\
\hline KVK SMS & 1.28 & 5 & 1.53 & 3 \\
\hline Dist level officials & 1.60 & 3 & 1.38 & 4 \\
\hline State level officials & 1.38 & 4 & 1.12 & 5 \\
\hline
\end{tabular}

Table.11 Use of mass media by tribal people as the source of information

\begin{tabular}{|l|l|c|c|c|c|}
\hline $\begin{array}{l}\text { SI } \\
\text { no }\end{array}$ & \multirow{2}{*}{ category } & \multicolumn{2}{|c|}{ WADI adopters } & \multicolumn{2}{|c|}{ WADI non adopters } \\
\cline { 3 - 6 } & & Frequency & Percentage & Frequency & Percentage \\
\hline $\mathbf{1}$ & Low & 5 & 8.3 & 20 & 33.4 \\
\hline $\mathbf{2}$ & Medium & 34 & 56.7 & 32 & 53.3 \\
\hline $\mathbf{3}$ & High & 21 & 35 & 8 & 13.3 \\
\hline \multicolumn{2}{|l|}{ Total } & $\mathbf{6 0}$ & $\mathbf{1 0 0}$ & $\mathbf{6 0}$ & $\mathbf{1 0 0}$ \\
\hline
\end{tabular}

MEAN $=13.5, \mathrm{SD}=2.5$ 
Table.12 Status of tribal people in use of mass media as source of information

\begin{tabular}{|l|c|c|c|c|}
\hline \multirow{2}{*}{ Mass media } & \multicolumn{2}{|c|}{ WADI adopters } & \multicolumn{2}{c|}{ WADI non-adopters } \\
\cline { 2 - 5 } & Mean score & Rank order & Mean score & Rank order \\
\hline News paper & 1.98 & 3 & 1.48 & 4 \\
\hline Periodicals & 1.00 & 5 & 1.00 & 5 \\
\hline Radio & 4.25 & 1 & 3.73 & 1 \\
\hline Television & 3.22 & 2 & 2.95 & 2 \\
\hline Films & 1.95 & 4 & 2.10 & 3 \\
\hline
\end{tabular}

Hence, it is clear that high user of mass media is more in case of WADI Tribal ones and less for the other group. The main reason behind this result is the level of awareness among the WADI tribal people and the level of education of a particular section of the society.

Table 12 concludes that for WADI adopting tribal people most preferred source of information was Radio (mean score: 4.25) followed by television (mean score: 3.22), Newspaper (mean score: 1.98), films (mean score: 1.95 ) and the least preferred one was periodicals (mean score: 1.00). But, for WADI non-adopting tribal people the most preferred source of information was radio (mean score: 3.73) followed by television (mean score: 2.95), films (mean score: 2.10), Newspaper (mean score: 1.48) and the least preferred one was periodicals having mean score of 1.00 .

In conclusion, the result obtained from the different social variable signifies that the role of WADI project in enhancing the development of certain social parameters of the WADI adopters as compared to the nonadopters. The former group stands in a higher position in the tribal society in respect to different socail characteristics like cosmopoliteness, social participation, organisational participation, extension contact and participation as well as the use and expose to different mass media channel. The results are so encouraging that it is recommended for the Government to implement more such project for the target group in other pockets of the nation.

\section{References}

A Study on the Livelihoods Situation Of the Tribal Communities in Raigad District of Maharashtra State by Resources and Livelihoods Group, Prayas, Pune, India. (2005) retrieved from https://prayaspune.org/reli/PUBLICA TIONS_files/B_1_3.pdf

Integrated Tribal Development Agency (ITDA - YANADIS) by Government of Andhra Pradesh retrieved from https://spsnellore.ap.gov.in/integratedtribal-development-agency-itdayanadis/

Pandey, A. K. (1997). Tribal Society in India, Manak Publications Pvt. Ltd., New Delhi.

Prasad. S. and Eswarappa (2005). Tribal livelihoods in a limbo: Changing Tribe nature Relationship in south Asia presented in eight sustainable development conference East Western, Islamabad.

Statistical Profile Of Scheduled Tribes In India (2013) by Ministry Of Tribal Affairs Statistics Division, Government Of India Retrieved from https://tribal.nic.in/ST/StatisticalProfil eofSTs2013.pdf

Tribal Development and Government schemes retrieved from https://shodhganga.inflibnet.ac.in/bitst 
ream/10603/91994/13/13_chapter\%20 6.pdf

Wadi project by M. S. Swaminathan Research Foundation retrieved from https://www.mssrfcabc.res.in/program s/livelihoods/wadi/index.html

Wadi: A model for sustainable tribal livelihood. (2015) retrieved from http://www.indiatogether.org/sustaina ble-tribal-livelihood-via-wadiagriculture

Yadav K. Integrated Tribal Development Agency (ITDA). (2010) retrieved from http://agropedia.iitk.ac.in/content/integ rated-tribal-development-agency-itda

\section{How to cite this article:}

Anupam Dakua1, R. N. Das and Kalyan Ghadei. 2020. Social Comparison of Tribal Groups Based on Wadi Project Adoption. Int.J.Curr.Microbiol.App.Sci. 9(08): 51-60.

doi: https://doi.org/10.20546/ijcmas.2020.908.006 